\title{
Research on Early Fire Smoke Movements and Detection Method in Stable Thermally Stratified Environments
}

\author{
FANG JUN, YUAN HONG-YONG, JI JIE, ZHANG YONG-MING, \\ and WEICHENG FAN \\ State Key Laboratory of Fire Science \\ University of Science and Technology of China \\ Anhui, Hefei 230026, People's Republic of China
}

\begin{abstract}
The movements of smoldering cotton wick smoke and flaming diesel oil smoke plumes in thermally stratified environments in a small scale enclosure were investigated by experiments and CFD simulations. The reasonably good agreements of the experimental and simulated results indicated that the thermally stratified environments intensified the decreases of the axial temperatures and velocities of a fire smoke plume. The previous integral equation was shown to underestimate the maximum smoke rises, and also unable to explain the differences of the maximum heights of low and high density smoke with the same stratification and outlet conditions. An improved integral equation and an effective detection method were introduced and discussed.
\end{abstract}

KEYWORDS: smoke plume, thermal stratification, integral equation, FDS, light section image detection

\section{INTRODUCTION}

In large volume spaces with high ceilings, due to the solar radiation, air conditioning system and the translucent glass structure, there is often a hot layer of air forming under the ceiling of an atrium, sometimes the hot air layer is very thick and the temperature gradient is big depending on the thermal load and building structure conditions. Due to the buoyant effects, the early fire smoke cannot breakthrough the stratified environments making the smoke detectors under the ceiling unable to respond.

To our knowledge, the available research work on early fire smoke movement and its detection in thermally stratified environments in large volume spaces is very little. The previous work of fire smoke movements in large spaces mainly focused on smoke filling and settlement process of a large fire by experimental measurements or zone modeling for smoke exhaust or egress time analysis [1-2]. The zone model is invalid in thermally stratified environments due to its assumption of uniform air conditions.

In NFPA 92B, the maximum smoke rise equation which only depends on the convective heat release rate and the ambient temperature variation in the space was derived by Morton in 1956 using an integral model as Eq. 1 describes [3].

$$
Z_{\max }=5.54 Q_{c}{ }^{1 / 4}(d T / d Z)^{-3 / 8},
$$

where $Z_{\max }$ is the maximum height of smoke plume (m), $Q_{c}$ is the convective portion of the fire heat release rate $(\mathrm{kW}), T$ is the ambient air temperature $(\mathrm{K}), Z$ is the vertical coordinate. 
The more accurate integral equation often takes the following form as Eq. 2 which is usually used to analyze the bubble movements in the stratified water [4].

$$
Z_{\max }=3.8 B_{0}{ }^{1 / 4} N^{-3 / 4},
$$

where $B_{0}$ is the thermal buoyant flux $\left(\mathrm{m}^{4} / \mathrm{s}^{3}\right), N$ is Brunt-Vaisälä buoyant frequency or stratified intensity $(\mathrm{Hz})$ as below

$$
N=\left(-\frac{g}{\rho_{a 0}} \frac{d \rho_{a}}{d Z}\right)^{1 / 2}
$$

here, $\rho_{a 0}$ is the reference air density $\left(\mathrm{kg} / \mathrm{m}^{3}\right)$, taken as the ambient air density near the fire source, $\rho_{a}$ is the ambient air density $\left(\mathrm{kg} / \mathrm{m}^{3}\right), g$ is the gravitational acceleration.

It is easy to prove that Eq. 1 comes from Eq. 2 by substituting the approximate formulas $B_{0}=g Q_{c} / \rho_{a 0} C_{p} T_{a 0}$ and $\rho_{a}=0.003484 P / T$ in it, here $C_{p}$ is the heat capacity at constant pressure $(\mathrm{J} /(\mathrm{kg} \mathrm{K})), T_{\mathrm{a} 0}$ is the ambient air temperature near the fire source, $P$ is the constant atmospheric pressure $(\mathrm{Pa})$.

The two important assumptions employed in Eq. 1 and Eq. 2 are the self-similarity and constant entrainment coefficient assumptions for a fully developed turbulent plume, which means that the time-average cross-sectional profiles of plume quantities (taken normal to the mean flow) maintain a fixed, near-Gaussian shape and a constant spreading rate [4]. And the influences of various fire materials upon the maximum heights are neglected.

The above maximum rise equations were not verified in real fire scenarios, except Haskestad's experiments about heptane fire in a temperature-stratified environment in a $3.66 \mathrm{~m} \times 3.66 \mathrm{~m}$ x $2.44 \mathrm{~m}$ high compartment room. In his study, the measurement method of the maximum heights was claimed to be responsible for the shortcomings of the maximum rise equation to underpredict the actual rises without more reasonable interpretations [5].

Early detection in large volume spaces with thermally stratified environments is a difficult task. In NFPA 92B the early detection schemes recommended are beam smoke detectors with enough units located at various horizontal and upward positions to detect the smoke at different levels and different angles regardless of the condition present at the time of fire initiation [3].

In this paper, we conducted many experiments with different fire materials in a small enclosure, and the integral equation was discussed and improved to agree with the experimental and CFD results. Finally an optical section image smoke detection method was proposed to detect the early fire in large volume spaces.

\section{EXPERIMENTS}

The experimental room is a $1.2 \mathrm{~m} \times 1.2 \mathrm{~m} \mathrm{x} 2 \mathrm{~m}$ high enclosure covered by organic glass materials and black cloth materials leaving a front face for observation and a vent for smoke exhaust as Fig. 1 shows. In the bottom there are small air gaps to keep a constant 
atmospheric pressure. A measuring scale was located along the axial direction to mark the smoke maximum rises. The stable linear stratifications were accomplished by preheating the enclosure air at different heating powers with fifteen evenly spaced quartz heating pipes under the ceiling of the enclosure.

The test fire materials are cotton wick which is one of the Europe standard fire materials and standard A55 diesel oil, they can produce low density smoke and high density smoke typically.

The outlet velocities were obtained with a high speed camera (SPEEDCAM Pro-Lt) working at 100 frames per second by using its image analysis software to calculate the ratios of two frontal surface heights of a rising plume to the needed time. The maximum heights of the plume were obtained by analyzing the plume images captured by a digital camera. The axial temperatures and the ambient air temperatures of the smoke plume were obtained by three rows of digital thermometers (DS18B20) suspended respectively in the middle and at one side in the vertical direction of the enclosure as Fig. 2 shows.
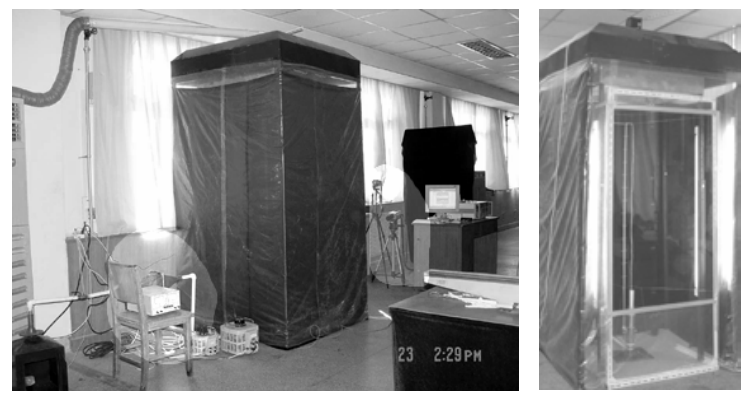

Fig. 1. Experimental setup and the front face of the enclosure.

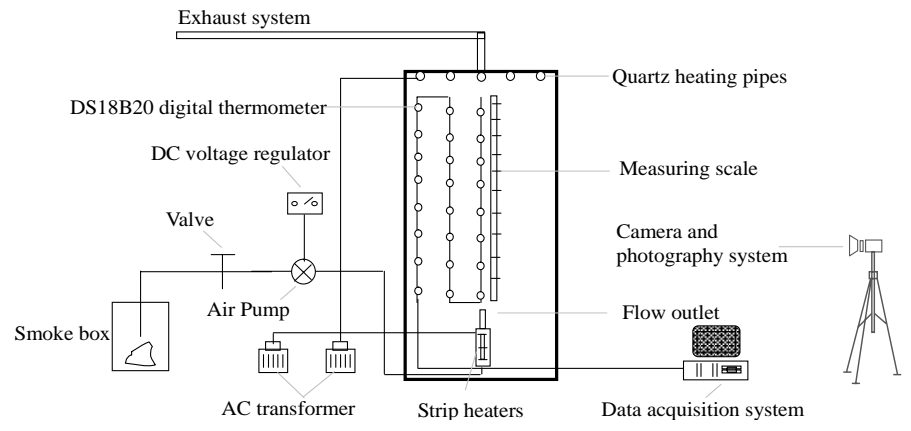

Fig. 2. Schematic plan of the experimental setup.

For the smoke outlet in the small enclosure, two schemes were adopted. Scheme 1 is that the fire smoke from the smoke box was pumped through a PVC pipe into an outlet device with strip heaters inside. The outlet device surface was thermally insulated to avoid thermal diffusion into the ambients and the device was put in the middle of the enclosure bottom. The outlet flow fluxes were adjusted with different heating powers, pump powers and different outlet diameters. This scheme not only can obtain different smoke rises of the same fire materials in different outlet and stratification conditions, but also can obtain different maximum rises of different fire materials in the same outlet conditions and stratifications to get more information than what NFPA 92B can give. 
The initial outlet and stratification conditions for smoldering cotton wick and flaming diesel oil smoke of scheme 1 and 2 are as Table 1 and Table 2 show respectively.

In scheme $1 \mathrm{for} \mathrm{a}, \mathrm{b}, \mathrm{c}, \mathrm{d}$, e, the outlet diameter is $1.5 \mathrm{~cm}$, for $\mathrm{A}, \mathrm{B}, \mathrm{C}, \mathrm{D}, \mathrm{E}$, the outlet diameter is $3 \mathrm{~cm}$. For each case, the outlet conditions and stratified environments are the same for smoldering cotton wick and flaming diesel oil smoke.

Scheme 2 is that the smoke box was put in the middle of the enclosure and the fire smoke entered the enclosure through a $2.5 \mathrm{~cm}$ diameter outlet directly.

Table 1. Initial outlet conditions and thermal environments of scheme 1.

\begin{tabular}{|c|c|c|c|c|c|c|c|}
\hline No. & $\begin{array}{c}\text { Outlet } \\
\text { ambient } \\
\text { temp. }\left(\mathbf{~}^{\mathbf{0}} \mathbf{C}\right)\end{array}$ & $\begin{array}{c}\text { Outlet } \\
\text { smoke temp. } \\
\mathbf{(} \mathbf{~} \mathbf{C})\end{array}$ & $\begin{array}{c}\text { Outlet } \\
\text { velocity } \\
\mathbf{( m / s )}\end{array}$ & $\begin{array}{c}\text { Outlet } \\
\text { thermal } \\
\text { buoyant flux } \\
\left(\mathbf{m}^{\mathbf{4}} / \mathbf{s}^{\mathbf{3}} \mathbf{)}\right.\end{array}$ & $\begin{array}{c}\text { Stratified } \\
\text { intensity } \\
\mathbf{( H z )}\end{array}$ & Gr & Re \\
\hline a & 18.0 & 22.25 & 0.521 & $1.1078 \mathrm{E}-05$ & 0.4511 & 2129.8 & 387.1 \\
\hline b & 17.5 & 25.0125 & 0.4 & $1.7463 \mathrm{E}-05$ & 0.4847 & 3771.5 & 507.43 \\
\hline c & 18.1 & 23.125 & 0.5125 & $1.4050 \mathrm{E}-05$ & 0.4470 & 2568.3 & 559.78 \\
\hline d & 17.5 & 30.0625 & 0.5971 & $4.2650 \mathrm{E}-05$ & 0.4846 & 1255.0 & 625.03 \\
\hline e & 18.5 & 30.0625 & 0.6667 & $4.0479 \mathrm{E}-05$ & 0.5958 & 1000.6 & 358.57 \\
\hline A & 17.5 & 19.5 & 0.18 & $9.8580 \mathrm{E}-06$ & 0.4985 & 12048.0 & 653.53 \\
\hline B & 17.6 & 24.7125 & 0.3333 & $5.3511 \mathrm{E}-05$ & 0.5093 & 28112.0 & 464.25 \\
\hline C & 18.5 & 25.625 & 0.2411 & $3.3571 \mathrm{E}-05$ & 0.6286 & 28015.6 & 580.93 \\
\hline D & 19.1 & 29.125 & 0.3077 & $6.0850 \mathrm{E}-05$ & 0.6519 & 39953.7 & 478.37 \\
\hline E & 18.1 & 23.875 & 0.2411 & $3.1997 \mathrm{E}-05$ & 0.5200 & 23553.5 & 514.14 \\
\hline
\end{tabular}

Table 2. Initial outlet conditions and thermal environments of scheme 2.

\begin{tabular}{|c|c|c|c|c|c|c|c|c|}
\hline No. & $\begin{array}{c}\text { Material } \\
\text { and } \\
\text { combustion }\end{array}$ & $\begin{array}{c}\text { Outlet } \\
\text { ambient } \\
\text { temp. } \\
\left({ }^{\circ} \mathrm{C}\right)\end{array}$ & $\begin{array}{c}\text { Outlet } \\
\text { smoke } \\
\text { temp. } \\
\left({ }^{\circ} \mathrm{C}\right)\end{array}$ & $\begin{array}{c}\text { Outlet } \\
\text { velocity } \\
\text { (m/s) }\end{array}$ & $\begin{array}{c}\text { Outlet } \\
\text { thermal } \\
\text { buoyant } \\
\text { flux } \\
\left(\mathrm{m}^{4} / \mathrm{s}^{3}\right)\end{array}$ & $\begin{array}{c}\text { Stratified } \\
\text { intensity } \\
(\mathrm{Hz})\end{array}$ & Gr & $\mathbf{R e}$ \\
\hline 1 & \multirow{4}{*}{$\begin{array}{l}\text { Smoldering } \\
\text { cotton wick }\end{array}$} & 24.25 & 48.5 & 0.1052 & 3.6285E-05 & 0.6201 & 35477.05 & 147.26 \\
\hline 2 & & 24.25 & 47 & 0.1221 & 4.1040E-05 & 0.5457 & 35643.34 & 171.49 \\
\hline 3 & & 25.56 & 64 & 0.1334 & 7.1328E-05 & 0.6213 & 47829.14 & 171.03 \\
\hline 4 & & 24.50 & 56.3 & 0.1302 & $6.0391 \mathrm{E}-05$ & 0.5655 & 43477.13 & 175.95 \\
\hline 1 & \multirow{2}{*}{$\begin{array}{l}\text { Flaming } \\
\text { diesel oil }\end{array}$} & 24.4 & 74.2 & 0.135 & 7.5899E-05 & 0.7376 & 52472.13 & 167.08 \\
\hline 2 & & 24.4 & 72.8 & 0.131 & 7.4064E-05 & 0.6440 & 52090.63 & 162.77 \\
\hline
\end{tabular}

NUMERICAL SIMULATIONS

The computer code used for the simulation was FDS (Fire Dynamic Simulator-Version 3) developed by BFRL of NIST (National Institute of Standards and Technology). FDS 
solves numerically a form of the Navier-Stokes equations appropriate for low speed, thermally-driven flow with an emphasis on smoke plume and heat transport from fires. Turbulence is treated by means of the Smagorinsky form of large eddy simulation.

In our simulations, as the smoke entered into the enclosure through an outlet, the highest smoke temperature is less than $100^{\circ} \mathrm{C}$, so the chemical reactions and the radiation effects were neglected. The initial temperature gradients of the stratifications were set according to the temperature measurements at different heights in the experiments; the outlet velocities were also set according to the observed outlet velocities. Both the smoldering smoke and the flaming smoke were assumed to be a gaseous mixture, but different from the assumptions for the calculations of the initial parameters in the experiments, here the smoldering cotton wick smoke and the flaming diesel oil smoke were assumed to be gaseous mixtures with different molecular weights.

As there are small air gaps in the enclosure bottom, small open air vents were also set in simulations. The walls of the enclosure were assumed approximately insulated with a small specific heat value to absorb heat flux and keep the temperature gradient steady.

\section{ANALYSIS AND COMPARISONS}

The experiments found that in the early time the smoke plume affected the ambient temperature gradients a little and expanded its radius gradually due to the air entrainment, and finally spread horizontally and stopped at a maximum height like a mushroom cloud.

The typical experimental and simulated mushrooms of cotton wick smoke and diesel oil are as Fig. 3 and Fig. 4 show. And the typical axial velocity, axial and ambient temperature are illustrated as Fig. 5 shows.
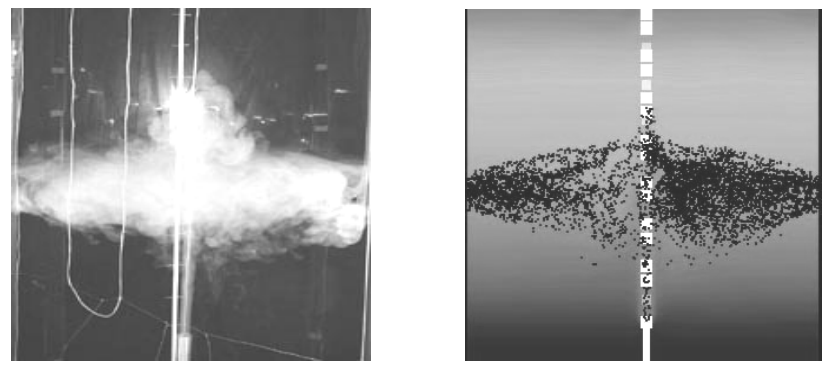

Fig. 3. Typical experimental photograph (left) and simulated contour (right) of a cotton wick smoke mushroom.
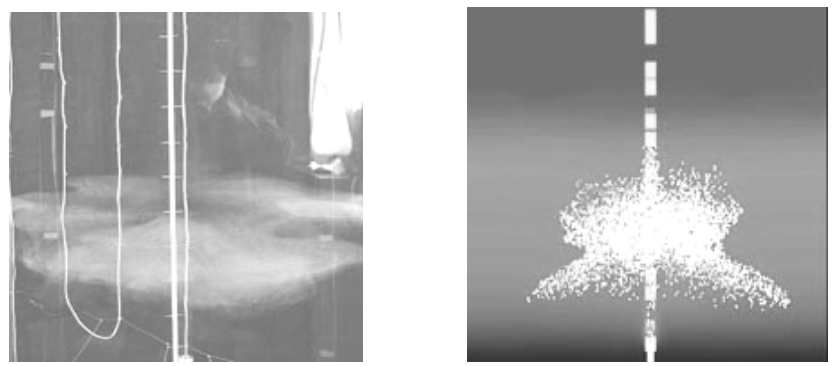

Fig. 4. Typical experimental photograph (left) and simulated contour (right) of a diesel oil smoke mushroom. 

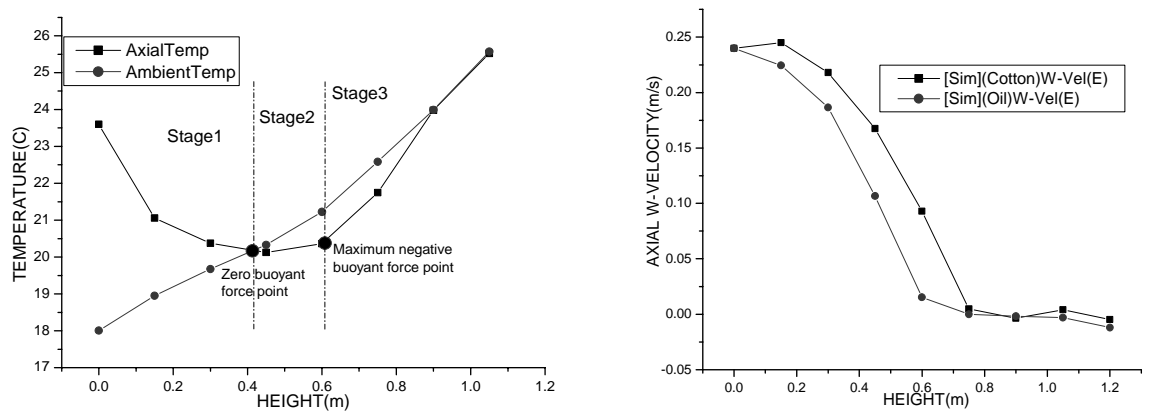

Fig. 5. Typical experimental temperatures (left) of scheme 1 and 2, and simulated axial velocities (right) of cotton wick and diesel oil smoke in scheme 1.

For each case of different fire materials in scheme 1 and scheme 2, the experimental results of the axial smoke velocities and temperatures, ambient air temperatures and maximum heights agree well with the simulated results respectively.

From the typical profiles of the experimental axial and ambient temperatures of scheme 1 and 2 in Fig. 5 we can see, the smoke plume development process can be typically divided into three stages.

(1) In Stage 1, the smoke outlet temperature is much greater than the local ambient air temperature and the buoyant force is positive, but the axial smoke temperature decreases quickly because of the plume entraining movement until it intersects with the ambient temperature curve at the first crossing point indicating the buoyant force reaches zero.

(2) In Stage 2, the smoke plume still rises because of its inertia and the continuing decreasing axial temperature causes the buoyant force to be negative. Due to the further hotter ambient air entrainment, the axial temperature gradually increases, but the negative buoyant force still increases until to reach a peak value at the maximum negative buoyant force point, and the axial velocity decreases more quickly.

(3) In Stage 3, the increasing axial temperature makes the negative buoyant force become smaller and the axial smoke temperature approaches the ambient air temperature gradually.

To verify the Bubble Movement Model, the experimental maximum heights of cotton wick and diesel oil smoke in scheme 1 and 2 are as Fig. 6 and Fig. 7 show.

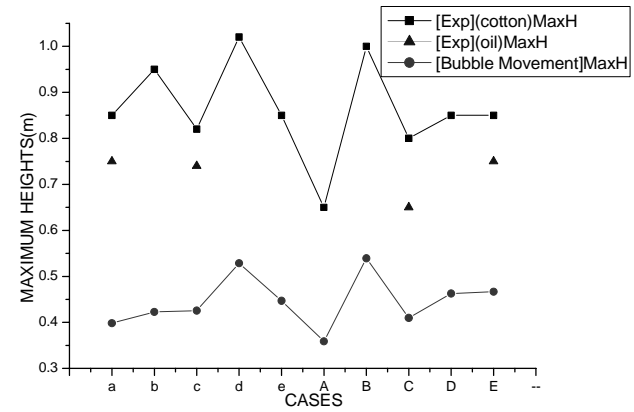

Fig. 6. Maximum heights of experiments and Bubble Movement Equation of scheme 1. 



Fig. 7. Maximum heights of experiments and

Bubble Movement Equation of scheme 2.

For the different fire materials with the same outlet and ambient conditions, the axial velocity of diesel oil smoke plume decreases faster than that of cotton wick smoke at the same heights as Fig. 5 shows. For the maximum heights of different fire materials, as Fig. 6 and Fig. 7 shows, the maximum heights of cotton wick smoke plume are always a little larger than those of the diesel oil smoke plume with the same outlet and ambient conditions, and the experimental maximum results are far bigger than the corresponding integral modeling results.

From Fig. 5 to Fig. 7 we can see, the Bubble Movement Equation is invalid to obtain the maximum heights of the test materials and is unable to predict the differences of the cotton wick smoke and diesel oil smoke movements. In Hestestad's study, the experimental heights were proved to be bigger than the theoretical values, and the excess height was 25 percent of the theoretical reach thought to be caused by the measurement mistake of the "bulge" height of the plume, while in our work, the difference increased to be almost 100 percent of the theoretical value far bigger than the "bulge" height [5].

\section{IMPROVED INTEGRAL EQUATION}

The failure of the previous integral equations in predicting the actual maximum rises should be first due to the self-similarity of a fully developed turbulent smoke plume. For a smoke plume induced by early fire, the plume is not fully turbulent near the fire source, and there is a certain distance proportional to the fire source size to satisfy the selfpreserving distributions of the vertical velocities and smoke concentrations [6].

Furthermore, for the same convective heat flux of a fire smoke plume with different smoke densities in the same thermally stratified environment, there are some differences in the maximum rises for the low density smoke or high density smoke plume.

So, to consider the influences of different densities and the requirements of self-similarity of a smoke plume, Eqs. 1 and 2 are modified as Eqs. 4 and 5 respectively.

$Z_{\text {max }}{ }^{\prime}=k_{1} \cdot\left[5.54 Q_{c}^{1 / 4}\left(\frac{d T_{a}}{d Z}\right)^{-3 / 8}\right]+k_{2} \cdot d_{0}$,

or 
$Z_{\text {max }}{ }^{\prime}=k_{1} \cdot\left(3.8 B_{0}{ }^{1 / 4} N^{-3 / 4}\right)+k_{2} \cdot d_{0}$,

where $k_{1}$ is the smoke density correction factor between 0 and 1 , defined as the maximum rise ratio of plumes in the same outlet and stratification conditions with and without considering the smoke density effect, $k_{2}$ is the self-similarity correction factor between 6 and 62 [6], defined as the height proportion factor for a turbulent plume to reach selfsimilar state, $d_{0}$ is the equivalent diameter of a fire source size.

The maximum heights and correction factors are as Table 3 and Table 4 show. From them and Table 1, and 2 we can see, the self-similarity factors are mainly related to Grashof number, it is because Gr number can more reflect the combination effect of buoyant force and viscosity force, which is characteristic of the transition process of a plume [7].

Table 3. Maximum heights and correction factors of cotton smoke of scheme 1, 2.

\begin{tabular}{|c|c|c|c|c|c|}
\hline $\begin{array}{l}\text { Material and } \\
\text { scheme }\end{array}$ & Case & $\begin{array}{c}\text { Outlet } \\
\text { diameter } \\
d_{0}(\mathrm{~m})\end{array}$ & $\begin{array}{l}\text { Experimental } \\
\text { maximum rise } \\
(\mathrm{m})\end{array}$ & $\begin{array}{c}\text { Integral } \\
\text { maximum rise } \\
(\mathrm{m})\end{array}$ & $k_{2}$ \\
\hline \multirow{10}{*}{$\begin{array}{l}\text { Cotton } \\
\text { (scheme 1) }\end{array}$} & $\mathrm{a}$ & 0.015 & 0.85 & 0.398 & 30.1145 \\
\hline & $\mathrm{b}$ & 0.015 & 0.95 & 0.423 & 35.141 \\
\hline & C & 0.015 & 0.82 & 0.405 & 27.628 \\
\hline & $\mathrm{d}$ & 0.015 & 1.02 & 0.528 & 32.753 \\
\hline & e & 0.015 & 0.85 & 0.447 & 26.87 \\
\hline & A & 0.03 & 0.65 & 0.279 & 12.370 \\
\hline & B & 0.03 & 1 & 0.589 & 13.696 \\
\hline & $\mathrm{C}$ & 0.03 & 0.8 & 0.410 & 13.009 \\
\hline & $\mathrm{D}$ & 0.03 & 0.85 & 0.463 & 12.913 \\
\hline & $\mathrm{E}$ & 0.03 & 0.85 & 0.466 & 12.775 \\
\hline \multirow{4}{*}{$\begin{array}{l}\text { Cotton } \\
\text { (scheme 2) }\end{array}$} & 1 & 0.025 & 0.78 & 0.422 & 11.918 \\
\hline & 2 & 0.025 & 0.83 & 0.479 & 11.639 \\
\hline & 3 & 0.025 & 0.81 & 0.499 & 10.439 \\
\hline & 4 & 0.025 & 0.92 & 0.514 & 13.453 \\
\hline
\end{tabular}

Table 4. Maximum heights and correction factors of diesel oil smoke of scheme 1, 2.

\begin{tabular}{|l|c|c|c|c|c|r|}
\hline \multirow{2}{*}{$\begin{array}{c}\text { Material and } \\
\text { scheme }\end{array}$} & No. & $\begin{array}{c}\text { Outlet } \\
\text { diameter } \\
\mathbf{d}_{\mathbf{0}} \mathbf{( m )}\end{array}$ & $\begin{array}{c}\text { Experimental } \\
\text { Maximum rise } \\
\mathbf{( m )}\end{array}$ & $\begin{array}{c}\text { Integral } \\
\text { maximum } \\
\text { rise (m) }\end{array}$ & $\boldsymbol{k}_{\mathbf{2}}$ & $\boldsymbol{k}_{\mathbf{1}}$ \\
\hline \multirow{3}{*}{$\begin{array}{l}\text { Diesel oil } \\
\text { (scheme 1) }\end{array}$} & $\mathrm{a}$ & 0.015 & 0.75 & 0.3983 & 30.11 & 0.74892 \\
\cline { 2 - 7 } & $\mathrm{C}$ & 0.015 & 0.74 & 0.4056 & 27.63 & 0.80275 \\
\cline { 2 - 7 } & $\mathrm{C}$ & 0.03 & 0.69 & 0.4097 & 13.01 & 0.73152 \\
\cline { 2 - 8 } & $\mathrm{E}$ & 0.03 & 0.75 & 0.4667 & 12.78 & 0.78574 \\
\hline \multirow{2}{*}{$\begin{array}{l}\text { Diesel oil } \\
\text { (scheme 2) }\end{array}$} & 1 & 0.025 & 0.63 & 0.4456 & 11.2 & 0.78 \\
\cline { 2 - 8 } & 2 & 0.025 & 0.70 & 0.4904 & 12.1 & 0.82 \\
\hline
\end{tabular}

In a real large volume space, the temperature gradient is often as Fig. 8 shows [8]. As the thermal buoyant flux in the constant temperature zone keeps constant, the actual 
maximum heights in the constant temperature and the adjacent convective zone of a fire smoke can be written as Eqs. 6 and 7 show.

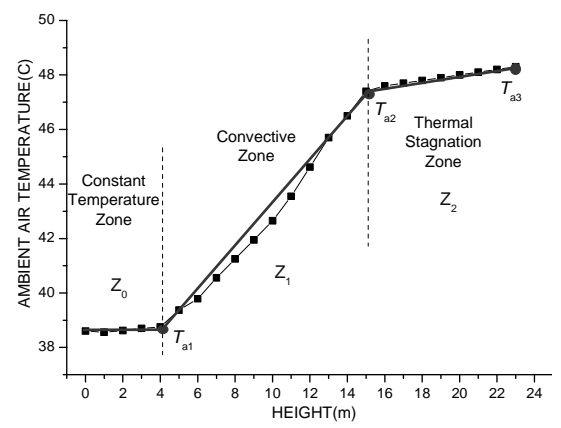

Fig. 8. Temperature gradient in a large volume space.

$Z_{\text {max }}{ }^{\prime \prime}=Z_{0}+k_{1} \cdot\left[5.54 Q_{c}{ }^{1 / 4}\left(\frac{d T_{a}}{d Z}\right)^{-3 / 8}\right]+k_{2} \cdot d_{0}$

$Z_{\text {max }}{ }^{\prime \prime}=Z_{0}+k_{1} \cdot\left(3.8 B_{0}{ }^{1 / 4} N^{-3 / 4}\right)+k_{2} \cdot d_{0}$,

here, the virtual origin of a fire plume is not considered, for virtual origin is often relative to a large flaming combustion, and for a plume induced by early fire of flaming combustion or smoldering combustion, the fire plume are a weak plume with a point source and the virtual origin effect can be neglected.

To verify the validity of Eq. 6, CFD simulations of propane combustions were conducted in a $30 \mathrm{~m} \times 30 \mathrm{~m} \times 24 \mathrm{~m}$ big space with different stratified environments. The typical smoke contours in linear and nonlinear stratified ambients are as Fig. 9 shows. The axial velocities of fire plumes in different stratification conditions are as Fig. 10 shows. For large fires, the initial temperature difference between fire smoke and ambient air is big and the entrainment movement is strong enough to destroy the stratified environment more or less, so the fire smoke directly reaches the ceiling in the early time to make the integral model invalid.


Fig. 9. Fire plumes with $5 \mathrm{~kW}$ convective heat release rate in linear (left) and nonlinear (right) air temperature gradient ambients. 
For all the cases within the reach of the integral modeling, the available equation underpredicts the maximum heights, and $k_{2}$ is about 7 . And for the same fire powers in different linear stratified environments, the maximum rises in nonlinear stratified environments are about 5 meters higher than those in linear stratified environments, which is the constant temperature zone height and coincides with the theoretically validated result of Eq. 6 in a certain way.
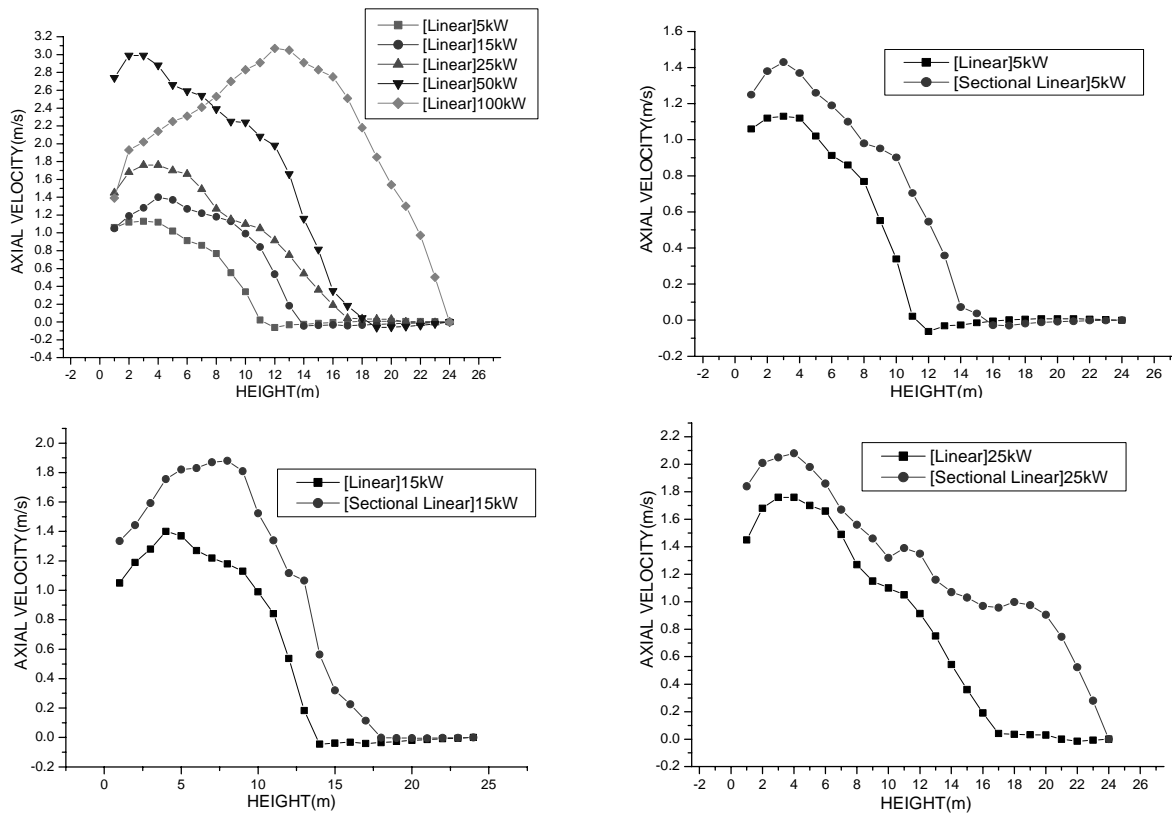

Fig. 10. Axial velocities of fire plumes with different convective heat release rates in linear and nonlinear stratified environments.

\section{EARLY FIRE SMOKE DETECTION IN LARGE VOLUME SPACES}

As the early fire smoke may suspend at a maximum height in a high large volume spaces, the conventional spot and light beam smoke detectors under the ceilings are difficult to detect the smoke effectively. So we propose an optical section image smoke detection system that is our patented invention as Fig. 11 shows [9]. This system consists of light emitters/receivers and a signal processing unit. The light emitters are a lot of infrared illuminators and the corresponding receivers are several infrared cameras. When the fire smoke flows across the infrared light beam, the facula in the pictures taken by the cameras will get weak in luminosity. Then the host computer can analyze these pictures using a certain algorithm to judge whether a fire has happened and give a signal to the interlock controller to activate fire suppression facilities such as water guns.

For high large volume spaces, there can be emitters and receivers in more than two planes to form a three dimensional optical smoke detection network to guarantee immediate response of a fire in the early time.

The lowest position of the detection plane should be lower than the maximum height of a possible fire, and the maximum height can be determined by the above improved integral 
equation combining the ambient air conditions and the fire powers of different combustible materials.

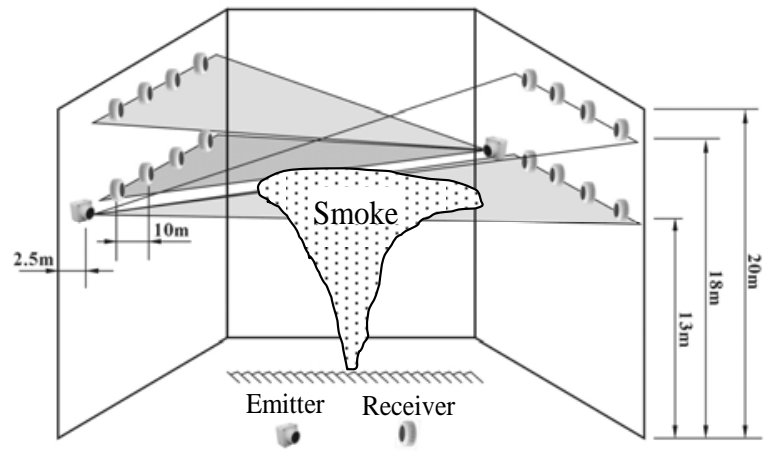

Fig. 11. Typical optical section image smoke detection layout.

Compared with the conventional detectors, the advantages of the patented invention are:

(1) The infrared radiation arrays and cameras can cover the protected space in arbitrary curved surface easily, so the protected area is greatly increased to detect early fires.

(2) Correlation analysis for adjacent beams in the light section can eliminate the error alarm caused by accidental factors, while convectional beam detectors respond to a threshold easily disturbed by them.

(3) The shift of operating conditions caused by dust accumulation is detected and traced automatically, and can automatically modify the operating parameters to adapt to the environments, so that the error and missed alarm caused by the dust accumulation and the environmental variation are reduced significantly.

(4) Surface imaging auto-tracing fixed-point detection can solve the problems of the error alarm caused by installing and moving the conventional linear smoke-sensing unit.

(5) By using the technique of surface imaging, this method is more capable of distinguishing an emitting light source from an interference light source than the conventional beam detectors could.

\section{SUMMARY AND CONCLUSIONS}

A detailed study of smoke plumes of smoldering cotton wick and flaming diesel oil in linear thermal stratifications was carried out by experiments and CFD simulations. The results show that the stratifications intensified the decreases of the axial temperatures and velocities of a fire smoke plume until made it terminate at a certain height.

By analyzing the differences between the maximum heights of the cotton wick smoke and the diesel oil smoke plumes with the same outlet and stratification conditions, as well as the big differences between the experimental and integral results, the previous integral equation was improved to consider the influences of the stratifications, smoke property and plume turbulence, which is verified by the FDS simulations in a large space. And it is important to the engineering application of an understanding of smoke plumes in stratified environments for replacing the NFPA92B equation by the improved equation. 
To avoid missing and false alarms of early fire smoke in high large space buildings, an optical section image smoke detection method with a three-dimensional observation net was proposed to overcome the shortcomings of conventional spot and beam smoke detectors.

\section{ACKNOWLEDGEMENTS}

The authors deeply appreciate the support of National Natural Science Fund Project under Grant No.50476023 and the Tenth Five-year National Key Science and Technology Project under Grant No.2004BA803B03-4.

\section{REFERENCES}

[1] Mowrer, F.W., “Enclosure Smoke Filling Revisited,” Fire Safety J., 33, pp. 93114, (1999).

[2] Chow et al., "Natural Smoke Filling in Atrium with Liquid Pool Fires up to 1.6 MW,” Building and Environment., 36, pp. 121-127, (2001).

[3] NFPA, "Guide for Smoke Management Systems in Malls, Atria, and Large Areas,” NFPA 92B-2000, National Fire Protection Association, Quincy, MA, 2000, p.73.

[4] Turner, J.S., "Turbulent Entrainment: the Development of the Entrainment Assumption, and its Application to Geophysical Flows," J.Fluid Mech., 173, pp. 431-471, (1986).

[5] Heskestad, G., "Fire Plume Behavior in Temperature-stratified Ambients," Combustion Sci. and Tech., 106, pp. 207-228, (1995).

[6] Dai, Z., Tseng, L.K., and Faeth, G.M., "Velocity/mixture Fraction Statistics of Round, Self Preserving, Buoyant Turbulent Plumes," National Heat Transfer Conference, 1995, pp.19-33.

[7] Bill, R.G., and Gebhart, B., "The Transition of Plane Plumes," Int.J.Heat Mass Transfer, 18, pp. 513-526, (1975).

[8] Huang Chen. "Research on Temperature Distributions of the Ambient Air in a Large Space Building,” Ph.D. Thesis, University of Science and Technology of Shanghai, 2001 [in Chinese].

[9] Yuan, et al. "Method for Detecting Fire with Light Section Image to Sense Smoke,” United States Patent, 2003, 6, pp. 611, 207. 